\title{
Does the form of the Aggregate Production Function Matter for Modelling Business Cycle Fluctuations? Lessons for Bulgaria (1999-2018)
}

\author{
Aleksandar Vasilev* \\ Lecturer, Lincoln International Business School, UK.
}

\begin{abstract}
We introduce a constant-elasticity-of-substitution (CES) production function into a real-business-cycle setup with a government sector. We calibrate the model to Bulgar- ian data for the period following the introduction of the currency board arrangement (1999-2018). We investigate the quantitative importance of the degree of substitutabil- ity between labor and capital in the aggregate production function, and found that aspect to matter relatively little for the ability of the model to match the magnitude of the observed business cycle fluctuations.
\end{abstract}

Keywords: business cycles, CES aggregate production function, Bulgaria.

JEL Classification Codes: E24, E32

\section{INTRODUCTION AND MOTIVATION}

The benchmark real-business-cycle (RBC) setup assumes that the production side can be represented by an aggregate production function, and that function takes the so-called Cobb- Douglas (CD) specification. However, the CobbDouglas form is a limit case of a much more general functional form, namely, the so-called" constant elasticity of substitution" (CES) function. Most of the research in the RBC literature utilizes the Cobb-Douglas form due to its analytical tractability and is thus a convenient choice, despite the fact that it is empirically-driven, and without a strong theoretical basis. ${ }^{1}$ However, it could be the case that by focusing on the Cobb-Douglas form, researchers have given up a lot of modelling flexibility, especially for a model element that lacks detailed theoretical derivation from micro-foundations. ${ }^{2}$

We take this proposal seriously, and incorporate the CES functional form for the production function in an otherwise standard real-business-cycle (RBC) model with a detailed govern- ment sector. We think that the analysis of business cycle issues should be always performed in a general equilibrium setup. We calibrate the model for Bulgaria in the period 1999- 2018, as Bulgaria (being the poorest EU member state, and a former transition economy, which is still developing)

*Address correspondence to this author at Lecturer, Lincoln International Business School, UK; E-mail: AVasilev@lincoln.ac.uk

\footnotetext{
${ }^{1}$ Empirical studies are also inconclusive whether the true functional form is Cobb-Douglas, or a generalized CES.

${ }^{2}$ There are also economists, who argue that the aggregate production function does not exist, and is part of the ideology (Felipe and McCombie 2013). We will not tackle this question here. We will only focus on the usefulness of the aggregate production function formulation as a tool, or model ingredient, that helps economists model the economy and answer questions that are relevant for macroeconomics.
}

provides a good testing case for the theory. We then proceed to quantitatively evaluate the effect of the parameter determining the degree of substitutability between capital and labor. The novelty in this paper is the explicit pursuit of the ques- tion whether the shape of the aggregate production function matters quantitatively for the ability of the model to generate aggregate fluctuations of the same magnitude as in data, and whether researchers have been putting too much trust in the Cobb-Douglas specification.

The two specifications of the aggregate production function will be subjected to a "horse race", the first study on the issue, and thus an important contribution to the field. Unfortunately, for reasonable degree of capital-labor substitutability in the aggregate production function, the quantitative effects are rather small. Therefore, the gains from using a more general function forms are not worth the cost of complicating the model, as the setup does not pro- vide new insights.

The rest of the paper is organized as follows: Section 2 describes the model framework and describes the decentralized competitive equilibrium system, Section 3 discusses the calibra- tion procedure, and Section 4 presents the steady-state model solution. Sections 5 proceeds with the out-of-steadystate dynamics of model variables, and compared the simulated second moments of theoretical variables against their empirical counterparts. Section 6 concludes the paper.

\section{MODEL DESCRIPTION}

There is a representative households which derives utility out of consumption and leisure. The time available to households can be spent in productive use or as leisure. The government taxes consumption spending, and levies a common proportional ("flat") tax on labor and capital income in order to finance wasteful purchases of government consumption goods, and government transfers. On the production side, there is a representative firm, which hires labor and capital to 
produce a homogeneous final good, which could be used for consumption, investment, or government purchases.

\subsection{Households}

There is a representative household, which maximizes its expected utility function

$\max E_{0} \sum_{t=0}^{\infty} \beta^{t}\left\{\ln c_{t}+\gamma \ln \left(1-h_{t}\right)\right\}$

whereE0 denotes household's expectations as of period 0 , ct denotes household's private con- sumption in period $\mathrm{t}$, ht are hours worked in period $\mathrm{t}, 0<\beta<1$ is the discount factor, 0 $<\gamma<1$ is the relative weight that the household attaches to leisure. $^{3}$

The household starts with an initial stock of physical capital $\mathrm{k} 0>0$, and has to decide how much to add to it in the form of new investment. The law of motion for physical capital is

$\mathrm{kt}+1=\mathrm{it}+(1-\delta) \mathrm{kt}$

and $0<\delta<1$ is the depreciation rate. Next, the real interest rate is rt, hence the before-tax capital income of the household in period $t$ equals rtkt. In addition to capital income, the household can generate labor income. Hours supplied to the representative firm are rewarded at the hourly wage rate of wt, so pre-tax labor income equals wtht. Lastly, the household owns the firm in the economy and has a legal claim on all the firm's profit, $\pi \mathrm{t}$.

Next, the household's problem can be now simplified to

$\max E_{0} \sum_{t=0}^{\infty} \beta^{t}\left\{\ln c_{t}+\gamma \ln \left(1-h_{t}\right)\right\}$

s.t.

$\left(1+\tau^{c}\right) c_{t}+k_{t+1}-(1-\delta) k_{t}=\left(1-\tau^{y}\right)\left[r_{t} k_{t}+\pi_{t}+w_{t} h_{t}\right]+g_{t}^{t}$

where $\tau c$ is the tax on consumption, $\tau y$ is the proportional income tax rate on labor and capital income $(0<\tau \mathrm{c}, \tau \mathrm{y}<t)$, and gt denotes government transfers. The household takes the tax rates $\{\tau \mathrm{c}, \tau \mathrm{y}\} \infty \mathrm{t}=0$, government spending categories, $\{\mathrm{gc}, \mathrm{gt}\} \infty$, profit $\{\pi \mathrm{t}\} \infty \mathrm{t}=0$,

the realized technology process $\{$ At $\} \propto t=0$, prices $\{w t$, $\mathrm{rt}\} \infty \mathrm{t}=0$, and chooses $\{\mathrm{ct}, \mathrm{ht}, \mathrm{kt}+1\} \infty \mathrm{t}=0$ to maximize its utility subject to the budget constraint. ${ }^{4}$

The first-order optimality conditions as as follows:

$c_{t}: \frac{1}{c_{t}}=\lambda_{t}\left(1+\tau^{c}\right)$

\footnotetext{
${ }^{3}$ This utility function is equivalent to a specification with a separable term containing government con- sumption, e.g. Baxter and King (1993). Since in this paper we focus on the exogenous (observed) policies, and the household takes government spending as given, the presence of such a term is irrelevant. For the sake of brevity, we skip this term in the utility representation above.

${ }^{4}$ Note that by choosing $k_{t+1}$ the household is implicitly setting investment $i_{t}$ optimally.
}

$$
\begin{aligned}
& h_{t}: \frac{\gamma}{1-h_{t}}=\lambda_{t}\left(1-\tau^{y}\right) w_{t} \\
& k_{t+1}: \quad \lambda_{t}=\beta E_{t} \lambda_{t+1}\left[\left(1-\tau^{y}\right) r_{t+1}-\delta\right]
\end{aligned}
$$

$T V C: \lim _{t \rightarrow \infty} \beta^{t} \lambda_{t} k_{t+1}=0$

where $\lambda t$ is the Lagrangean multiplier attached to household's budget constraint in period

t. The interpretation of the first-order conditions above is as follows: the first one states that for each household, the marginal utility of consumption equals the marginal utility of wealth, corrected for the consumption tax rate. The second equation states that when choosing labor supply optimally, at the margin, each hour spent by the household working for the firm should balance the benefit from doing so in terms of additional income generates, and the cost measured in terms of lower utility of leisure. The third equation is the so-called "Euler condition," which describes how the household chooses to allocate physical capital over time. The last condition is called the "transversality condition" (TVC): it states that at the end of the horizon, the value of physical capital should be zero.

\subsection{Firm Problem}

There is a representative firm in the economy, which produces a homogeneous product. The price of output is normalized to unity. The production technology is Constant Elasticity of Substitution and uses both physical capital, kt, and labor hours, ht, to maximize static profit

$$
\Pi_{t}=A_{t}\left[\alpha k_{t}^{\rho}+(1-\alpha) h_{t}^{\rho}\right]^{1 / \rho}-r_{t} k_{t}-w_{t} h_{t}
$$

where At denotes the level of technology in period t, and $\rho$ is the substitutability parameter.5 Since the firm rents the capital from households, the problem of the firm is a sequence of static profit maximizing problems. In equilibrium, there are no profits, and each input is priced according to its marginal product, i.e.:

$$
\begin{gathered}
k_{t}: \quad \alpha k_{t}^{\rho} \frac{y_{t}}{\alpha k_{t}^{\rho}+(1-\alpha) h_{t}^{\rho}}=r_{t}, \\
h_{t}:(1-\alpha) h_{t}^{\rho} \frac{y_{t}}{\alpha k_{t}^{\rho}+(1-\alpha) h_{t}^{\rho}}=w_{t} .
\end{gathered}
$$

In equilibrium, given that the inputs of production are paid their marginal products, $\pi \mathrm{t}=0, \forall \mathrm{t}$.

\subsection{Government}

In the model setup, the government is levying taxes on labor and capital income, as well as consumption, in order to fi-

\footnotetext{
${ }^{5}$ Note that $1 /(1-\rho)$ is the elasticity of substitution; $\rho \rightarrow 0$ is the limitcase resulting in a Cobb-Douglas specificationfortheproductionfunction. Similarly, $\rho \rightarrow 1$ yieldsalinearproductionfunction, wherecapital andlabor are perfect substitutes in the production of output. This case, however, is nota good description for technology at aggregate level, as the two inputs are complements at macro-level.
} 
nance spending on wasteful government purchases, and govern- ment transfers. The government budget constraint is as follows:

$g_{t}^{c}+g_{t}^{t}=\tau^{c} c_{t}+\tau^{y}\left[w_{t} h_{t}+r_{t} k_{t}+\pi_{t}\right]$

consumption tax rate, income tax rate and government consumption-to-output ratio would be chosen to match the average share in data, while government transfers would be deter- mined residually in each period so that the government budget is always balanced.

\subsection{Dynamic Competitive Equilibrium (DCE)}

For a given process followed by technology $\left\{A_{t}\right\}_{t=0}^{\infty} \operatorname{tax}$ schedules $\left\{\tau^{c}, \tau^{l} \tau^{k}\right\}_{t=0}^{\infty}$, and ini- tial capital stock $\{\mathrm{k} 0\}$, the decentralized dynamic competitive equilibrium is a list of se- quences $\left\{c_{t}, i_{t}, k_{t}, h_{t}\right\}_{t=0}^{\infty}$ for the household, a sequence of government purchases and transfers $\left\{g_{t}^{c}, g_{t}^{t}\right\}_{t=0}^{\infty}$ and input prices $\left\{w_{t}, r_{t}\right\}_{t=0}^{\infty}$ such that (i) the household maximizes its utility function subject to its budget constraint; (ii) the representative firm maximizes profit; (iii) government budget is balanced in each period; (iv) all markets clear.

\section{DATA AND MODEL CALIBRATION}

To characterize business cycle fluctuations in Bulgaria, we will focus on the period following the introduction of the currency board (1999-2018). Quarterly data on output, consump- tion and investment was collected from National Statistical Institute (2019), while the real interest rate is taken from Bulgarian National Bank Statistical Database (2019). The cal- ibration strategy described in this section follows a long-established tradition in modern macroeconomics: first, as in Vasilev (2016), the discount factor, $\beta=0.982$, is set to match the steady-state capital-to-output ratio in Bulgaria, $\mathrm{k} / \mathrm{y}$ $=13.964$, in the steady-state Euler equation. The labor share parameter, $1-\alpha=0.571$, is obtained as in Vasilev (2017d), and equals the average value of labor income in aggregate output over the period 1999-2018. This value is slightly higher as compared to other studies on developed economies, due to the overaccumulation of physical capital, which was part of the ideology of the totalitarian regime, which was in place until 1989. Next, the average labor and capital income tax rate was set to $\tau$ ya $=0.1$. This is the average effective tax rate on income between 1999-2007, when Bulgaria used progressive income taxation, and equal to the proportional income tax rate introduced as of 2008. Similarly, the average tax rate on consumption is set to its value over the period, $\tau \mathrm{c}$ $=0.2$. The value of the substitution parameter is set to $\rho=$ 0.26

\footnotetext{
${ }^{6}$ Given the inconclusiveness of empirical studies, this value is chosen, as we want a small departure from the CD case $(\rho=0)$, while at the same time the model needs to stay sufficiently away from the $\rho=1$ case, where capital and labor are perfect substitutes, as at aggregate level the two inputs are actually complements. In section 5, as a robustness check, we experiment with different values for $\rho$.
}

Next, the relative weight attached to the utility out of leisure in the household's utility function, $\gamma$, is calibrated to match that in steady-state consumers would supply one-third of their time endowment to working. This is in line with the estimates for Bulgaria (Vasilev 2017a) as well over the period studied. Next, the depreciation rate of physical capital in Bulgaria, $\delta=0.013$, was taken from Vasilev (2016). It was estimated as the average quar- terly depreciation rate over the period 1999-2014. Finally, the process followed by the TFP process is estimated from the detrended series by running an AR(1) regression and saving the residuals. Table 1 below summarizes the values of all model parameters used in the paper.

Table 1: Model Parameters

\begin{tabular}{|c|c|c|c|}
\hline Parameter & Value & Description & Method \\
\hline$\beta$ & 0.982 & Discount factor & Calibrated \\
\hline$\alpha$ & 0.429 & Capital Share & Data average \\
\hline $1-\alpha$ & 0.571 & Labor Share & Calibrated \\
\hline$\gamma$ & 0.873 & Relative weight attached to leisure & Calibrated \\
\hline$\delta$ & 0.013 & Depreciation rate on physical capital & Data average \\
\hline$\tau^{y}$ & 0.100 & Average tax rate on income & Data average \\
\hline$\tau$ & 0.200 & VAT/consumption tax rate & Data average \\
\hline$\rho$ & 0.200 & Substitution parameter & Set \\
\hline$\rho_{a}$ & 0.701 & AR(1) persistence coefficient, TFP & Estimated \\
\hline$\sigma_{a}$ & 0.044 & st. errocess & Estimated \\
\hline
\end{tabular}

\section{STEADY-STATE}

Once the values of model parameters were obtained, the steady-state equilibrium system solved, the "big ratios" can be compared to their averages in Bulgarian data. The results are reported in Table 2 below. The steady-state level of output was normalized to unity (hence the level of technology A differs from one, which is usually the normalization done in other studies), which greatly simplified the computations. Next, the model matches consumption- to-output and government purchases ratios by construction; The investment ratios are also closely approximated, despite the closedeconomy assumption and the absence of foreign trade sector. The shares of income are also identical to those in data, which is an artifact of the assumptions imposed on functional form of the aggregate production function. The after-tax return, where $\mathrm{r}^{-}=(1-\tau y) \mathrm{r}^{-} \delta$ is also relatively well-captured by the model. Lastly, given the absence of debt, and the fact that transfers were chosen residually to balance the government budget constraint, the result along this dimension is understandably not so close to the average ratio in data.

\section{OUT OF STEADY-STATE MODEL DYNAMICS}

Since the model does not have an analytical solution for the equilibrium behavior of variables outside their steady-state values, we need to solve the model numerically. This is done 
by log-linearizing the original equilibrium (non-linear) system of equations around the steady- state. This transformation produces a first-order system of stochastic difference equations.

Table 2. Data Averages and Long-run Solution.

\begin{tabular}{|c|c|c|c|}
\hline Variable & Description & Data & Model \\
\hline$y$ & Steady-state output & N/A & 1.000 \\
\hline$c / y$ & Consumption-to-output ratio & 0.648 & 0.674 \\
\hline$i / y$ & Investment-to-output ratio & 0.201 & 0.175 \\
\hline$k / y$ & Capital-to-output ratio & 13.96 & 13.96 \\
\hline$g^{c} / y$ & Government consumption-to-output ratio & 0.151 & 0.151 \\
\hline$w h / y$ & Labor income-to-output ratio & 0.571 & 0.571 \\
\hline$r k / y$ & Capital income-to-output ratio & 0.429 & 0.429 \\
\hline$h$ & Share of time spent working & 0.333 & 0.333 \\
\hline$r^{-}$ & After-tax net return on capital & 0.014 & 0.016 \\
\hline
\end{tabular}

First, we study the dynamic behavior of model variables to an isolated shock to the total factor productivity process, and then we fully simulate the model to compare how the second moments of the model perform when compared against their empirical counterparts.

\subsection{Impulse Response Analysis}

This subsection documents the impulse responses of model variables to a $1 \%$ surprise inno- vation to technology. The impulse response functions (IRFs) are presented in Fig. 1 and Fig. 2 for the CES- and Cobb-Douglas production functions, respectively. As a result of the one-time unexpected positive shock to total factor productivity, output increases upon impact. This expands the availability of resources in the economy, so used of output - con- sumption, investment, and government consumption also increase contemporaneously. The impulse responses are almost identical to the responses in a model with a Cobb-Douglas specification, so the quantitative effect of the substitution parameter $\rho$ is rather small.

At the same time, the increase in productivity increases the after-tax return on the two factors of production, labor and capital. The representative households then respond to the incentives contained in prices and start accumulating capital, and supplies more hours worked. In turn, the increase in capital input feeds back in output through the production function and that further adds to the positive effect of the technology shock. In the labor market, the wage rate increases, and the household increases its hours worked. In turn, the increase in total hours further increases output, again indirectly.
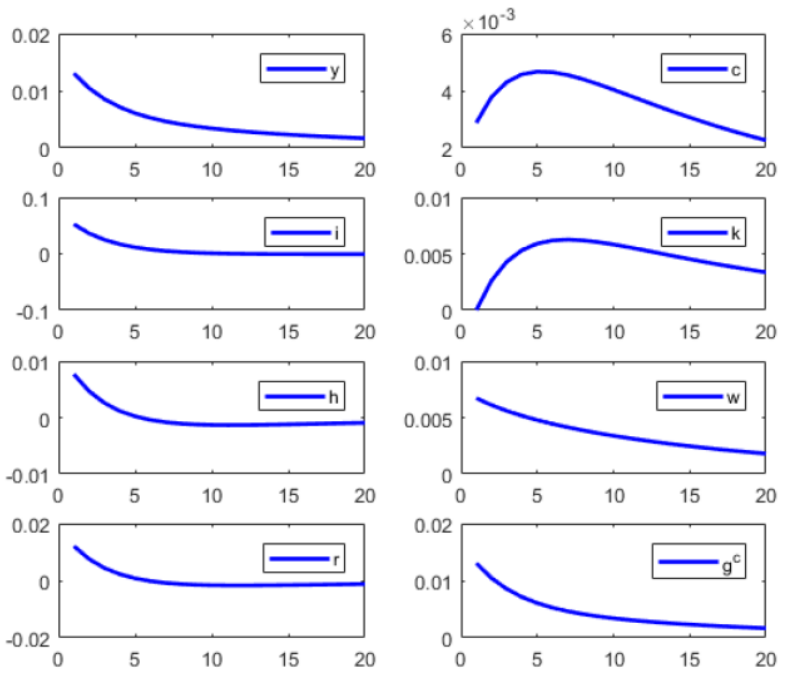

Fig. (1). Impulse Responses to a 1\% surprise innovation in technology (CES production function, $\rho=0.3$ )

Over time, as capital is being accumulated, its after-tax marginal product starts to decrease, which lowers the households' incentives to save. As a result, physical capital stock eventually returns to its steady-state, and exhibits a humpshaped dynamics over its transition path. The rest of the model variables return to their old steady-states in a monotone fashion as the effect of the one-time surprise innovation in technology dies out.
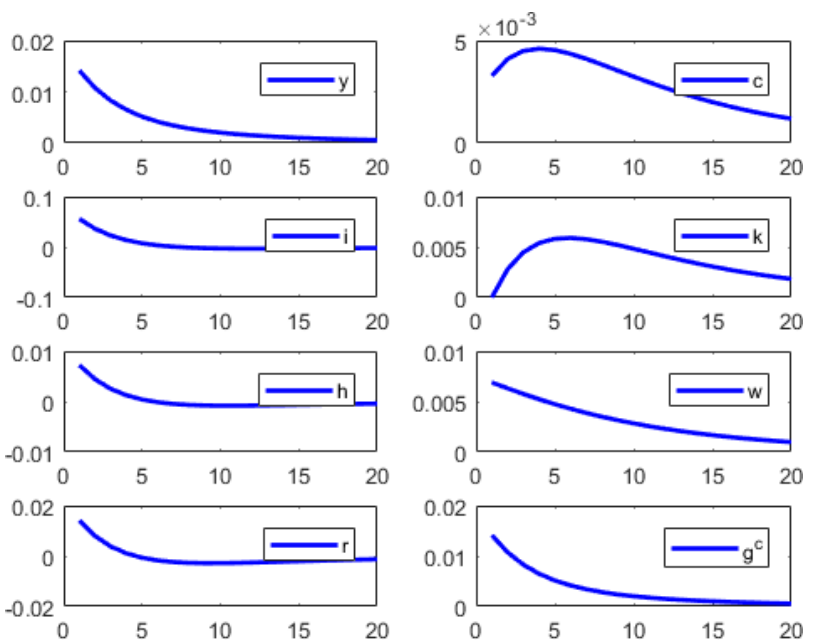

Fig. (2). Impulse Responses to a 1\% surprise innovation in technology (Cobb-Douglas pro- duction function).

\subsection{Simulation and Moment-Matching}

As in Vasilev (2017b), we will now simulate the model 10,000 times for the length of the data horizon. Both empiri$\mathrm{cal}$ and model simulated data is detrended using the HodrickPrescott (1980) filter. Table 3 on the next page summarizes the second moments of data (relative volatilities to output, and contemporaneous correlations with output) versus the same mo- ments computed from the model-simulated data at quarterly frequency. The "Model" is the case with a CES production function, for several realistic values for $\rho$, while 
the "Benchmark RBC" is a setup with a Cobb-Douglas production function, which corresponds to the CES specification with $\rho \rightarrow 0$. In addition, to minimize the sample error, the simulated moments are averaged out over the computergenerated draws. As in Vasilev (2016, 2017b, 2017c), all models match quite well the absolute volatility of output. By construction, government consumption in the model varies as much as output. In addition, the predicted consumption and investment volatilies are too high. Still, the models are qualitatively consistent with the stylized fact that consumption generally varies less than output, while investment is more volatile than output. With an increase in substitutability between labor and capital in the production function, hours react more. In particular, when $\rho \in[0,3,0.4]$, investment and employment volatility is a bit closer to data. Still, for smaller positive values for $\rho$, the models are almost indistinguishable from one another.

Table 3. Business Cycle Moments.

\begin{tabular}{|c|c|c|c|c|c|c|}
\hline & Data & Model & Model & Model & Model & $\begin{array}{c}\text { Benchmark } \\
\text { RBC }\end{array}$ \\
\cline { 2 - 7 } & & $(\boldsymbol{\rho}=\mathbf{0 . 1})$ & $(\boldsymbol{\rho}=\mathbf{0 . 2})$ & $(\boldsymbol{\rho}=\mathbf{0 . 3})$ & $(\boldsymbol{\rho}=\mathbf{0 . 4})$ & $(\boldsymbol{\rho}=\mathbf{0})$ \\
\hline$\sigma_{y}$ & 0.05 & 0.05 & 0.05 & 0.05 & 0.05 & 0.05 \\
\hline$\sigma_{c} / \sigma_{y}$ & 0.55 & 0.83 & 0.82 & 0.82 & 0.84 & 0.82 \\
\hline$\sigma_{i} / \sigma_{y}$ & 1.77 & 2.30 & 2.33 & 2.29 & 2.22 & 2.35 \\
\hline$\sigma_{g} / \sigma_{y}$ & 1.21 & 1.00 & 1.00 & 1.00 & 1.00 & 1.00 \\
\hline$\sigma_{h} / \sigma_{y}$ & 0.63 & 0.28 & 0.28 & 0.32 & 0.38 & 0.28 \\
\hline$\sigma_{w} / \sigma_{y}$ & 0.83 & 0.86 & 0.84 & 0.81 & 0.76 & 0.86 \\
\hline $\operatorname{corr}(c, y)$ & 0.85 & 0.90 & 0.90 & 0.91 & 0.91 & 0.90 \\
\hline $\operatorname{corr}(i, y)$ & 0.61 & 0.83 & 0.83 & 0.82 & 0.82 & 0.83 \\
\hline $\operatorname{corr}(g, y)$ & 0.31 & 1.00 & 1.00 & 1.00 & 1.00 & 1.00 \\
\hline $\operatorname{corr}(h, y)$ & 0.49 & 0.47 & 0.49 & 0.11 & -0.07 & 0.59 \\
\hline $\operatorname{cor}(w, y)$ & -0.01 & 0.97 & 0.96 & 0.98 & 0.98 & 0.96 \\
\hline $\operatorname{corr}(w, h)$ & -0.14 & 0.25 & 0.27 & -0.08 & -0.22 & 0.36 \\
\hline
\end{tabular}

With respect to the labor market variables, the variability of employment predicted by the models is lower than that in data, but the variability of wages in the models is very close to that in data. This is yet another confirmation that the perfectly-competitive assumption,

e.g. Vasilev (2009), as well as the benchmark calibration here, does not describe very well the dynamics of labor market variables. Next, in terms of contemporaneous correlations, the model systematically over-predicts the procyclicality of the main aggregate variables - con- sumption, investment, and government consumption. This, however, is a common limitation of this class of models. Along the labor market dimension, the contemporaneous correlation of em- ployment with output is a bit too low, especially for larger $\rho$ values. With respect to wages, the model predicts strong cyclicality, while wages in data are acyclical. This shortcoming is well-known in the literature. Lastly, in terms of the wage-hours correlation, some departure from the CobbDouglas case helps the model approximate better data along this dimension.

In the next subsection, as in Vasilev (2016), we investigate the dynamic correlation be- tween labor market variables at different leads and lags, thus evaluating how well the model matches the phase dynamics among variables. In addition, the autocorrelation functions (ACFs) of empirical data, obtained from an unrestricted VAR(1) are put under scrutiny and compared and contrasted to the simulated counterparts generated from the model.

\subsection{Auto- and Cross-Correlation}

This subsection discusses the auto-(ACFs) and crosscorrelation functions (CCFs) of the major model variables. The coefficients empirical ACFs and CCFs at different leads and lags are presented in Table 4 on the next page against the averaged simulated AFCs and CCFs for the best calibration case, i.e. when $\rho=0.3$. $^{7}$

As seen from Table $\mathbf{4}$ on the next page, the CES model compares relatively well vis-a-vis data. Empirical ACFs for output and investment are slightly outside the confidence band predicted by the model, while the ACFs for total factor productivity and household consumption are wellapproximated by the model. The persistence of labor market variables are also relatively well-described by the model dynamics. Overall, the model with a CES production function generates too much persistence in output and employment, and is subject to the criticism in Nelson and Plosser (1992), Cogley and Nason (1995) and Rotemberg and Woodford (1996b), who argue that the RBC class of models do not have a strong internal propagation mechanism besides the strong persistence in the TFP process. In those models, e.g. Vasilev (2009), and in the current one, labor market is modelled in the Walrasian market-clearing spirit, and output and employment persistence is low.

Table 4. Autocorrelations for Bulgarian data and the model economy.

\begin{tabular}{|c|c|c|c|c|c|}
\hline \multicolumn{2}{|c|}{} & $\mathbf{k}$ & \multicolumn{2}{|c|}{} \\
\hline Method & Statistic & $\mathbf{0}$ & $\mathbf{1}$ & $\mathbf{2}$ & $\mathbf{3}$ \\
\hline Data & $\operatorname{corr}\left(n_{t}, n_{t-k}\right)$ & 1.000 & 0.484 & 0.009 & 0.352 \\
\hline Model & $\operatorname{corr}\left(n_{t}, n_{t-k}\right)$ & 1.000 & 0.954 & 0.897 & 0.833 \\
\hline & $($ s.e. $)$ & $(0.000)$ & $(0.029)$ & $(0.056)$ & $(0.081)$ \\
\hline Data & $\operatorname{corr}\left(y_{t}, y_{t-k}\right)$ & 1.000 & 0.810 & 0.663 & 0.479 \\
\hline Model & $\operatorname{corr}\left(y_{t}, y_{t-k}\right)$ & 1.000 & 0.956 & 0.905 & 0.847 \\
\hline & $($ s.e. $)$ & $(0.000)$ & $(0.026)$ & $(0.051)$ & $(0.074)$ \\
\hline
\end{tabular}

\footnotetext{
${ }^{7}$ Following Canova (2007), this is used as a goodness-of-fit measure.
} 


\begin{tabular}{|c|c|c|c|c|c|}
\hline Data & $\operatorname{corr}\left(a_{t}, a_{t-k}\right)$ & 1.000 & 0.702 & 0.449 & 0.277 \\
\hline Model & $\operatorname{corr}\left(a_{t}, a_{t-k}\right)$ & 1.000 & 0.955 & 0.898 & 0.834 \\
\hline & $($ s.e. $)$ & $(0.000)$ & $(0.028)$ & $(0.055)$ & $(0.080)$ \\
\hline Data & $\operatorname{corr}\left(c_{t}, c_{t-k}\right)$ & 1.000 & 0.971 & 0.952 & 0.913 \\
\hline Model & $\operatorname{corr}\left(c_{t}, c_{t-k}\right)$ & 1.000 & 0.958 & 0.910 & 0.856 \\
\hline & $($ s.e. $)$ & $(0.000)$ & $(0.024)$ & $(0.046)$ & $(0.067)$ \\
\hline Data & $\operatorname{corr}\left(i_{t}, i_{t-k}\right)$ & 1.000 & 0.810 & 0.722 & 0.594 \\
\hline Model & $\operatorname{corr}\left(i_{t}, i_{t-k}\right)$ & 1.000 & 0.954 & 0.897 & 0.833 \\
\hline & $($ s.e. $)$ & $(0.000)$ & $(0.029)$ & $(0.055)$ & $(0.080)$ \\
\hline Data & $\operatorname{corr}\left(w_{t}, w_{t-k}\right)$ & 1.000 & 0.760 & 0.783 & 0.554 \\
\hline Model & $\operatorname{corr}\left(w_{t}, w_{t-k}\right)$ & 1.000 & 0.957 & 0.908 & 0.852 \\
\hline & $($ s.e. $)$ & $(0.000)$ & $(0.025)$ & $(0.048)$ & $(0.070)$ \\
\hline
\end{tabular}

Next, as seen from Table 5 on the next page, over the business cycle, in data labor productiv- ity leads employment. The model (again simulated with $\rho=0.3$ ), however, cannot account for this fact. As in the standard RBC model a technology shock can be regarded as a factor shifting the labor demand curve, while holding the labor supply curve constant. Therefore, the effect between employment and labor productivity is only a contemporaneous one.

Table 5. Dynamic Correlations for Bulgarian Data and the Model Economy.

\begin{tabular}{|c|c|c|c|c|c|c|c|c|}
\hline \multicolumn{2}{|c|}{} & $\mathbf{k}$ & \multicolumn{5}{|l|}{} \\
\hline Method & Statistic & $\mathbf{- 3}$ & $\mathbf{- 2}$ & $\mathbf{- 1}$ & $\mathbf{0}$ & $\mathbf{1}$ & $\mathbf{2}$ & $\mathbf{3}$ \\
\hline Data & $\begin{array}{c}\operatorname{corr}\left(h_{t},\right. \\
\left.(y / h)_{t-k}\right)\end{array}$ & -0.342 & -0.363 & -0.187 & -0.144 & 0.475 & 0.470 & 0.346 \\
\hline Model & $\begin{array}{c}\operatorname{corr}\left(h_{t},\right. \\
\left.(y / h)_{t-k}\right)\end{array}$ & 0.025 & 0.020 & 0.012 & -0.084 & -0.252 & -0.329 & -0.380 \\
\hline & $($ s.e. $)$ & $(0.351)(0.304)(0.249)(0.356)$ & $(0.292)(0.248)$ & $(0.317)$ \\
\hline Data & $\operatorname{corr}\left(h_{t}, w_{t-k}\right)$ & 0.355 & 0.452 & 0.447 & 0.328 & -0.040 & -0.390 & -0.57 \\
\hline Model & $\operatorname{corr}\left(h_{t}, w_{t-k}\right)$ & 0.025 & 0.020 & 0.012 & -0.084 & -0.252 & -0.329 & -0.380 \\
\hline & $($ s.e. $)$ & $(0.351)$ & $(0.304)$ & $(0.249)$ & $(0.356)$ & $(0.292)$ & $(0.248)$ & $(0.317)$ \\
\hline
\end{tabular}

\section{CONCLUSIONS}

We introduce a constant-elasticity-of-substitution (CES) production function into a real- business-cycle setup augmented with a detailed government sector. We calibrate the model to Bulgarian data for the period following the introduction of the currency board arrangement (1999-2018). We investigate the quantitative importance of the degree of sub- stitutability between labor and capital in the production function, and found that aspect to matter relatively little for the ability of the model to match the magnitude of the observed aggregate fluctuations.

\section{CONFLICT OF INTEREST STATEMENT}

The authors declare that they have no conflict of interest.

\section{REFERENCES}

Baxter, Marianne and Robert King. 1993. "Fiscal policy in general equilibrium," American Economic Review 83: 315-334.

Bulgarian National Bank. 2019. Bulgarian National Bank Statistics. Available on-line at www.bnb.bg. Accessed on July 21, 2019.

Canova, Fabio. 2007. Methods for Applied Macroeconomic Research Princeton Univer- sity Press: Princeton, NJ.

Cogley, Timothy and James Nason. 1995. "Output dynamics in RealBusiness-Cycles,"

American Economic Review 85(3): 492-511.

Di Nola, A., Kocharkov, G., and Vasilev, A. (2019) "Envelope wages, Hidden Production, and Labor Productivity," B.E. Journal of Macroeconomics (Advances), 19(2), pp.1-30.

Felipe, Jesus and McCombie, John S.L. (2013) The Aggregate Production Function and the Measurement of Technical Change: "Not Even Wrong". Edward Elgar Publishing: Chel- tenham, UK.

Hodrick, Robert and Edward Prescott. 1980. "Post-war US business cycles: An empiri- cal investigation." Unpublished manuscript (CarnegieMellon University, Pittsburgh, PA).

National Statistical Institute. 2019. Aggregate Statistical Indicators. Available on-line at www.nsi.bg. Accessed on July 21, 2019.

Rotemberg, Julio and Michael Woodford. 1996b. "Real-Business-Cycle Models and the Forecastable Movements in Output, Hours, and Consumption," American Economic Re- view, 86: 71-89.

Vasilev, A. (2017a) "Business Cycle Accounting: Bulgaria after the introduction of the cur- rency board arrangement (1999-2014), European Journal of Comparative Economics, 14(2): 197-219.

Vasilev, A. (2017b) "A Real-Business-Cycle model with efficiency wages and a government sector: the case of Bulgaria," Central European Journal of Economics and Econometrics, 9(4): 359-377.

Vasilev, A. (2017c) "A Real-Business-Cycle model with reciprocity in labor relations and fiscal policy: the case of Bulgaria," Bulgarian Economic Papers BEP 03-2017, Center for Economic Theories and Policies, Sofia University St. Kliment Ohridski, Faculty of Economics and Business Administration, Sofia, Bulgaria.

Vasilev, A. (2017d) "VAT Evasion in Bulgaria: A General-Equilibrium Approach," Review of Economics and Institutions, 8(2): 2-17.

Vasilev, A. (2017e). "Progressive taxation and (in)stability in an exogenous growth model with an informal sector," Journal of Economics and Econometrics 60(2): 1-13.

Vasilev, A. (2016a). "Progressive taxation and (in)stability in an endogenous growth model with human capital accumulation," Journal of Economics and Econometrics 59(2): 1-15.

Vasilev, A. (2016) "Search and matching frictions and business cycle fluctuations in Bul- garia," Bulgarian Economic Papers BEP 03-2016, Center for Economic Theories and Policies, Sofia University St. Kliment Ohridski, Faculty of Economics and Business Administration, Sofia, Bulgaria.

Vasilev, A. (2015a) "Welfare effects of flat income tax reform: the case of Bulgaria," Eastern European Economics 53(2): 205-220.

Vasilev, A. (2015b) "Welfare gains from the adoption of proportional taxation in a general- equilibrium model with a grey economy: the case of Bulgaria's 2008 flat tax reform," Eco- nomic Change and Restructuring, 48(2): 169-185.

Vasilev, A. (2009) "Business cycles in Bulgaria and the Baltic countries: an RBC approach,"

International Journal of Computational Economics and Econometrics, 1(2): $148-170$ 